\title{
Forgotten fluids of the reproductive tract
}

\author{
David F. Albertini
}

Published online: 29 May 2014

(C) Springer Science+Business Media New York 2014

For better or worse, progress in the sciences depends on advances in technology. The history of science, and society for that matter, is punctuated by the introduction and implementation of new technologies shaping and often irreversibly altering our perceptions of the natural world. And along the pathways of discovery that have led us to this point in the practice of human ARTs, many fundamental concepts of natural reproduction have been cast to the sidelines as a consequence of our drive to introduce and implement the latest "bells and whistles" emergent from the revolution of molecular genetics and high-throughput analytical platforms.

One context for examining this topic comes from the experience of having to move or relocate the laboratory, be it of the clinical embryology/andrology or basic science variety. There is no better time to evaluate current and future equipment needs, to reassess the ergonomics of lab design for optimizing staff performance, and for cleaning house of what has been accumulating for years in the form of expired media stocks, outdated plasticware, and any other number of things that the passionate and self-debilitating scientist has collected over the years.

House cleaning is a venture that for many a hoarder presents a dilemma. For a seasoned scientist who has spent several decades stockpiling reagents, equipment, and lab books, this indeed comes as a trying and yet unavoidable task when circumstances arise such that procrastination is no longer a viable option. With mixed blessings then is having to move a laboratory-hopefully into a new facility-one of those inevitable career-bending situations. Events of this kind

Capsule New research in mice raises important questions about how factors in seminal fluid influence female reproductive tract physiology and the health of offspring.

D. F. Albertini $(\bowtie)$

University of Kansas Medical Center, Kansas, KS, USA

e-mail: dalbertini@kumc.edu necessarily connote the not so pleasant aura of change attended by the realization that technology has evolved to a point that far exceeds the aging infrastructure at hand. And, reluctantly admitting so means it is time to discard any and all items that served so well in a day when science was performed by students, postdocs, fellows, and even PIs vested in making their own reagents, fixing their own equipment, and typing their own manuscripts and grants.

These vestiges of times gone by in the way science was done are hominid constructions that for whatever reasons continue to permeate the practice of science and medicine today, reaffirming our reductionist approach to solving problems. There was a time when basic scientists were applauded for purification of their favorite proteins from crude tissue homogenates resulting in a single chromatography peak and that elusive but tell-tale lonely band on a gel. From there, the protein hunters took their favorite subjects into the ear veins of many a rabbit and if lucky collected serum some weeks later that afforded them a new tool-an antibody that was specific to their intended target-and with this an opening to the next set of experiments that would almost guarantee another round of funding.

Things are so different now. Purification schemes rest within the purview of commercial vendors as have the choices of antibodies that you can order from any of a number of companies that take the "bleeding bunny" dimension of everyday science out of the picture and into the hands of accountants. Now, the purity of your antigen is attested to by catalogue renditions of a western blot and/or that sample image of your protein confined to that piece of a cell or area on a tissue section that makes obtaining such reagents as simple as a click of an electronic shopping cart-no more are minus 80 freezers stuffed with rabbit serum!

Hesitation does enter the decision-making part of the house cleaning commitment. What if a need will arise for the spectrophotometer with the temperature-regulated flow cell? Can 
one truly afford to discard the hundreds of tubes of rabbit serum or ascites samples of monoclonal antibodies that have served so well the needs of a laboratory through the halcyon years? Contending with the notion of throwing the baby out with the bathwater is a disconcerting one, a sentiment that portends finality and the demise of the way science was done 30 years ago.

But the one thing this exercise does bring to surface is the reinforcement of the idea that purity is a virtue in the sense of stripping complexity down to the very essence of what is required. Reduction to simplicity remains a directive in all branches of biomedical research whether the quest is for the development of new vaccines or in identifying the methylation changes in your favorite gene's promoter. The field of human ARTs is no exception!

Decades of research in reproductive science have sought to define the factors in follicular fluid, and continue today, that might offer a glimpse into the nature of the environs of the perfect egg or the transgressions that result in PCOS. So too has the reductionist approach be taken to define the composition of tubal or uterine fluids as sentinels of embryo quality or implantation potential. And it was not so long ago that driven by the use of ICSI, the decision was made to eliminate all of those cumulus cells to avail penetration with a single spermbearing micropipette.

And where did said spermatozoon come from? In best-case scenarios, it derived from an ejaculate stripped of all of its accoutrements kindly donated by the male reproductive tract secretions as semen. It passed the swimming test that placed it in an ICSI dish ready for facilitated fertilization under the watchful eyes of an experienced embryologist. And, one might ask, "Where has all the bathwater gone?" True, that seminal fluid too has suffered the same fate as those follicular aspirates and cumulus cells-gone and forgotten.

Our issue this month takes note of (and pays homage to) the forgotten fluids of reproductive medicine. Based on a study that appeared in the Proceedings of the National Academy of Science recently by Bromfield and colleagues (Maternal tract factors contribute to paternal seminal fluid impact on metabolic phenotype in offspring; www.pnas.org/cgi/doi/10.1073/ pnas.1305609111), our lead article takes the JARG readership on a journey back to the constituents of semen that, at least in mice, appear to have both an acute and long-term impact on the health of offspring, especially males.

In this article featured on our cover this month, Bromfield from the University of Florida reviews evidence supporting the idea that components in semen do much to alter the expression of genes in the female reproductive tract. Moreover, from whatever it is that influences the earliest stages of embryo development, an impact is registered on the metabolic health and fitness in male offspring. While much remains to be discovered in terms of connecting the dots between preimplantation development and offspring health, within and without of the context for human biology from an animal model, this topic serves well to again illustrate that the fluidic environments in which our gametes and embryos survive and perform embody a wealth of information that has yet to have been revealed and may play into the extraordinary series of events that define human fertility. 